chloroform rather than ether. On further inquiry I usually find that the preference for chloroform is really a case of "Hobson's choice." The practitioner has only given ether a few times as a student, some 20 or more years ago, or, perhaps, not at all, and in saying that he prefers to give chloroform he means that chloroform is the only anæsthetic with which he feels moderately sure of being able to anæsthetise the patient. The real reason why chloroform with its discreditable death-rate is so largely used is because a large percentage of practitioners do not know how to anæsthetise a patient with ether. Fortunately the public are beginning to appreciate the relative safety of ether over chloroform, so that, in time, medical men will be obliged either to learn how to administer ether or to run the risk of losing their patients. Medical men who lecture to the laity on such subjects as "ambulance" and "first aid" might with advantage substitute for the differential diagnosis of the various forms of unconsciousness and the diagnosis of fractures and dislocations a few plain remarks on the relative safety of ether over chloroform as a general anæsthetic, especially in dental cases. I am, Sirs, yours faithfully,

Plymouth, Sept. 25th, 1904.

C. HaMILTON WHITEFORD.

\section{FEVER IN CHILDREN CAUSED BY CARBOHYDRATE FOODS.}

\section{To the Editors of THE LANCET.}

SIRS, - I am sure Dr. Henry Davy's paper in The LANCET of Sept. 24th on the above subject has been read with interest by general practitioners whose work lies in any considerable degree amongst children. For myself the article had an enhanced interest in that $I$ have been keeping under observation a series of these cases with the hope of describing them later, the condition being one that comes more within the range of the general practitioner than of the consultant. Experience tends more and more to convince me that there is one factor seldom, if ever, absent in these attacks - a factor to which Dr. Davy makes but passing allusion-the presence of adenoid vegetations in the nasopharynx. Dr. Davy does not make it clear whether his encounter with the "very eminent throat specialist" who offered to remove his son's adenoids was a casual one and his offer purely speculative, or whether a digital examination was made of his son's naso-pharynx, this being the only reliable test for determining their presence or absence. He gives, however, the suggestive history of a severe attack of croup at two and a half years of age and of "colds during which he had a 'croupy cough ' and was feverish" occurring frequently until he was seven years old; also of the severity of an attack of whooping-cough and of the febrile attacks thenceforward becoming worse. This is a type of a common collateral history of adenoids.

The process by which these growths cause such febrile digestive disturbances is simple to explain. Thorough mastication with saliva is essential to the proper digestion of starchy foods and if the patient uses his mouth instead of his nose for respiration he is apt, in order to get his breath, to bolt instead of chew his mouthful. In addition to getting this periodic consignment of undigested starch along with some of the other articles of diet condemned by Dr. Eustace Smith (jams, sweet cakes, carrots, and the like) the stomach is receiving from the nasopharynx a continuous trickle of muco-purulent secretion. Anyone who has removed adenoids knows the oftentimes most offensive cheesy matter which has accumulated in the crypts of these growths. Yet another factor to be considered is the increasing tendency of parents to ply children who do not seem to thrive with the various non-, semi-, or whollypredigested starchy patent foods now so largely and persuasively advertised. (Dr. Harry Campbell makes some original and suggestive remarks in this regard in his article on the Evolution of Man's Diet in the current issue (Sept. 24th) of TH́E LANCET.) What more is required to bring about pathological fermentation with dilatation of the stomach, hepatic derangement, and the toxæmia and anæmia which accompany this condition? The state of affairs is very similar to that found in adults associated with oral sepsis from decayed teeth.

The occasional exacerbations are to be traced to such causes as an extra supply of indigestible food, reaction following excitement, the exactions of school life, fatigue, cold, or anything which may weaken the powers of resistance of the tissues to the toxins formed in the alimentary canal. I can see no necessity for relying on some obscure theory of pancreatic insufficiency to account for these attacks. Any inability of the pancreatic secretion to perform its function may be attributed to the high degree of fermentative acidity of the stomach contents when passed into the duodenum So much attention has been given to the effects of adenoid growths on the respiratory organs that their evil influence on digestion has not even yet received its due share of recognition. The improvement in digestion and assimilation after clearing the naso-pharynx is, however, as striking as it is gratifying. Nevertheless, the febrile attacks do not always disappear at once. Habits of efficient mastication are not established immediately nor does stomachic dilatation become reduced forthwith. But the attacks are, as a rule, much less severe and tend to pass off as the child develops, and possibly as Dr. Campbell's "lost pharyngeal reflex" (which I have looked for in vain in my own children) becomes re-established.

There is a type of digestive disturbance, often febrile, which bears a clinical resemblance in many respects to the foregoing and which occurs in children of neurotic diathesis who may have no trace of adenoids. They are apt to follow any nervous excitement, such as a children's party, and are commonly attributed by the parents to the consumption of indigestible cakes. I think that in these cases the cause is to be found in the baneful influence which excitement exerts on the digestive secretions and in the tendency under the same influence to bolt food without mastication; probably also there is some pyloric spasm. They differ from the form associated with adenoids in the febrile element not being so marked, in their more rapid response to treatment by dieting, rest, and hepatic stimulants, and in the absence or slight degree of gastrectasis. In the adenoid type, moreover, there is more of a toxæmic element, as evinced by the greater collapse, the nocturnal and often offensive perspiration about the head and upper half of the trunk, \&c. Furthermore, unless the child is living under the most favourable conditions, such as holiday making or careful dieting, there is in the adenoid type such evidence of digestive disturbance as poor or ravenous appetite between the attacks, whereas in the purely neurotic type it is commonly normal. I submit the foregoing observations as the outcome of my own experience, believing them on that account to have some measure of value. I trust that so distinguished a physician as Dr. Davy will not think me presumptuous or be in any way offended at the criticisms I have made bold to offer on his most interesting and valuable paper. I am, Sirs, yours faithfully,

J. S. Mackintosh, M.R.C.S. Eng., L.R.C.P. Lond. Hampstead, Sept. 24th, 1904

\section{THE BOILING OF MILK.}

\section{To the Editors of THE LANCET.}

SIRs,-In The LANCET of August 27tb, Sept. 10th, and Sept. 17th you print several letters more or less hinging on and dealing with, the prevention of infantile diarrhœa by treating milk presumably bacteriologically unsound with a view to rendering it fit for the food of the young. Dr T. R. Bradshaw and Mr. Cecil Revis advocate the addition of preservatives to milk, which appears to me to admit failure and surrender of buman ingenuity to circumstances over which greater control ought to exist. Dr A. S. Grünbaum very properly seriously calls in question the proposal of the above gentlemen. Dr. J. M. Fortescue-Brickdale and Mr. R. Bevan appear to advocate the boiling of milk as the simplest and best means of rendering it less toxic and pathogenic. Dr. R. Hingston Fox deals with the risk of scurvy as the result of paten foods and boiled milk and the same is mentioned by Dr. Fortescue-Brickdale and Mr. Bevan. As for boiled milk alone causing much scurvy or rickets, time and space preclude lengthy discussion, but I can confidently join issue with and strongly deny that boiling of milk is a considerable factor, if indeed a factor, in the causation of scurvy. I consider the question of boiled milk and scurvy the classical example in medical circles of "a little knowledge being a dangerous thing." The other day I met a junior member of the profession who had just had seven deaths in a month from "infantile diarrhoa" and was lamenting his fate. I asked 
him what he had done and he said that he had tried all the patent foods and that they were "no good" (most of us can remember the time when everybody's patent food "cured" infantile diarrhoea-according to the proprietors). suggested the efficacy of "boiling the milk" and every feed of milk. He retorted that he was told in hospital that boiled milk caused scurvy rickets, \&c. I asked him if he had ever seen a case from boiled milk and he said "Well, not that he could really rely on." My reply was, "Well, you have seen seven deaths from 'unboiled' milk." He was also astonished to hear that during my 15 years' close observation of the feeding of infants in private and hospital practice I had not seen one single case due to boiled milk; verb. sap. So long as we have two schools of thought -the boiled-milk-scurvy-rickets school and the other-side school-so long shall we have a heavy infantile death-rate from diarrhoea. In my book "Intestinal Intoxication in Infants" 1 I dealt fully with every problem commonly arising in the etiology, prevention, pathology, and treatment of infantile diarrhoea, and the materials were gleaned from a prolonged experience of private and hospital practice and many of the facts stated were the result of original research carried out during the greater part of my medical career. This emboldens me to join in this discussion and to make a suggestion which I have been putting into practice lately with success.

The putrescibility of milk-ordinary cow's milk-is the factor to be dealt with. Why not get rid of this by removing the "water" from the milk, and by using a good, sweet, natural, soluble, and palatable milk powder put an end to the summer-heat and ignorant-person difficulty? During June, July, August, and September, when the earth thermometer reaches a well-known elevation, is the time when milk is most lethal to infants. Why not feed the children of the poor and ignorant, who cannot carry out sterilising directions efficiently, on dried milk powder? Indeed, why not feed all children on dried milk during the heat of summer and at other times if necessary or desirable? Dried vaccine, antidiphtheritic serum, and antivenene can be preserved dry and yet be efficient. Why not do the same with milk? Hitherto it has been impossible to obtain a soluble, non-cheesy, non-mawkish, cheap milk powder.

Messrs. Freud and Co., of 19, St. Dunstan's-hill, London, E.C., have provided me with a soluble, fresh, palatable, and cheap natural milk powder which I have used with much success, and they will, I am sure, send samples of the same to those of your readers desiring it. This milk powder has the following advantages : (1) it is cheap; (2) it can be prepared as a food very quickly ; (3) it can be kept and transported to places where milk is difficult to obtain ; (4) it will keep sweet and fresh for long periods of time; (5) pure milk can be made from it at all times ; (6) it ensures the infant getting a "warm feed" and a non-poisonous one; (7) no more need be liquefied than is needed for a feed ; (8) it is as nutritious and safe as boiled fresh milk and less dangerous than the average milk in most houses ; (9) it cannot if kept dry be easily contaminated; (10) it can be used in any proportion as regards its albumin, fat, sugar, and salts ; (11) it can be used to prepare "humanised milk"; (12) it is prepared from fresh, sterilised, natural milk without precipitation and by the instantaneous evaporation of its water only, \&c. ; (13) I have not yet come upon any sound objection to its use ; (14) it is better than many samples of ordinary milk, for it is safe bacteriologically; and (15) it can be used turn about with good new milk, if new milk is scarce or is unobtainable, as during a hot night in summer. I trust that the above suggestions will provide material not for controversial purposes but to afford some means of combating what is, indeed, the most deadly scourge of infantile life.

I am, Sirs, yours faithfully,

F. W. Forbes Ross, M.D. Edin., F.R C.S. Eng., Gower-street, W.C. D.P.H. Lond., \&c.

\section{A VERY SIMPLE CONTRIVANCE TO AID MYOPIC AND OTHER FAILING EYES, ESPECIALLY IN READING.}

\section{To the Editors of THE LANCET.}

SIRs,-As with failing eyesight I have received, especially in reading, for some years very considerable assistance from a very simple contrivance it may help some of your readers over a difficulty if I state very briefly and in quite simple terms what $I$ have in view without subjecting it to any discussion on grounds of priority, as no doubt, it has occurred to many people before. My eyes have been very myopic all along and have required very strong concave lenses which, however, modified by the process of aging, kept me very comfortable and in a certain sense as well off as the average man up to about ten years ago when a separation of the retina occurred in the left eye which entirely destroyed it for practical purposes and left me dependent for vision on the other eye in which I found there was a commencing, but happily not a perceptibly advancing, cataract. 'The problem therefore now is how to use the remains of power in this right eye so as to persevere as much as possible with my reading which, owing to my other infirmities, is more and more important for me as an occupation. Ever since the commencement of old age I have found that reading is best done without any lens and at a distance of four or five inches from the page. It is by economising and aiding this limited visual power that I find the contrivance above referred to is of the greatest use. It consists simply of a conical tube of light pasteboard material so prepared as to have diameters at the side applied to the eye of two and a quarter by one and a quarter inches, while the diameters of the opposite end of the cone (the one nearest the book) measure one and a half by one inches, the length of the cone being approximately two and a half inches. The machine is held in place by a simple bit of elastic and is so cut as to be adapted to the eye of the side on which it is applied and blackened within by some opaque application shutting off all accidental or useless rays. To prevent undue friction the edge next the face is guarded by a little velveteen and so the job is at once complete and anyone can either make it for himself or get it made at any stationer's. Were there any demand for such articles they might easily be turned out at a cost of a few pence. The service done is entirely by shutting off side rays and limiting the vision in area with corresponding distinctness in detail. I can most truly say that for the last year or two this little invention has enabled me to continue a reader even of very moderatesized print under the difficulties above referred to.

Sept. 24th, 1904 I am, Sirs, yours faithfully,

\section{THE HYGIENE OF THE BARBER.}

\section{To the Editors of THE LANCET.}

SIRS,-In connexion with your article upon this subject in THE LANCET of Sept. 24th, p. 902, I should like to be allowed to point out that although the regulations which you suggest if strictly enforced would reduce to a minimum the risks which are now to be met with in a hairdresser's shop, there are still two other ways in which partial safety is to be found, at any rate in so far as hair-cutting is concerned. One way is by the establishment of visiting hairdressers who would use the personal brushes and combs of those they operated upon. I know of at least one hairdresser who gave up his shop and arranged with his customers to call upon them periodically at fixed dates. His charges were not raised, for he frequently attended upon several members of the same family at one visit and I believe he managed to make a fair income. Another way is to carry out a practice which is even now adopted to a limited extent, and that is to take one's own brush and comb when paying a visit to the hairdresser.

Sept. 27th, 1904 I am, Sirs, yours faithfully, HERBERT JONES。

\section{THE HOLMAN TESTIMONIAL FUND. To the Editors of THE LANCET.}

Sirs, - At a meeting of the committee held this afternoon it was decided to close the fund in a fortnight from the present date. In the meantime I may so far anticipate the final report as to state that the amount received will leave a net balance of a little over $\$ 400$ to be expended on the object to which it was decided that the fund should be devoted, the erection of a room in connexion with Epsom College which will be a reading-room for the boys out of school hours and will also serve as a studio in which drawing may be taught while they are in school.

The original estimate was $£ 500$ and while $£ 400$ can be made to serve the purpose it is greatly to be desired that the comfort and convenience and appearance of the room should 